\title{
Mechanical and Thermal Properties of Dental Resin Nanocomposite Material Polymerized by Diode Laser
}

\author{
Muna Y. Slewa* ${ }^{1}$, Thoalfiqar Ali Zaker ${ }^{2}$, Ban A.Bader ${ }^{3}$, Emad Toma Karash ${ }^{4}$ \\ \{1muna_ys@yahoo.com; ${ }^{2}$ thoalfiqar.physics@gmail.com ; ${ }^{3}$ banbader1971@gmail.com \\ ${ }^{4}$ Emadbane2007@yahoo.com $\}$ \\ ${ }^{1}$ Assistant Prof. / laser and photonics Research center / University of Hamdaniya , Nineveh , Iraq \\ ${ }^{2}$ Lecturer / laser and photonics Research center / University of Hamdaniya , Nineveh , Iraq \\ ${ }^{3}$ Lecturer / laser and photonics Research center / University of Hamdaniya , Nineveh , Iraq \\ ${ }^{4}$ Assistant Prof. / Northern Technical University, Nineveh, Iraq
}

\begin{abstract}
This paper evaluates the effect of continuous light and direct inversion of a two-wave laser valve to healing a resin-based material: Ivoclar Vivadent Tetric Nano Ceram Light Cured Hybrid renovated composite material on hardness, compression strength and temperature rise properties. Hardness was determined by (Amsler, KARLKOLB/Germany) tester. Compression was determined by a universal testing and high temperature was measured using, the type L digital thermocouple. Samples are prepared then curing with irradiation time $(10,20,30,40,50$, and 60) Sec. The results obtained on the average (hardness, compressive strength and temperature) velocity of the Tetric NCeram composite resin composite disc polymerised with a diode laser as a function of exposure, compared with usage statistics (linear logarithmic, quadratic, linear and power). Diode Laser showed the highest mechanical property values and minimum temperature recorded in the reflective laser diode method was $20 \mathrm{c}$, the maximum temperature through direct method for a diode laser irradiation was $5.4^{\circ} \mathrm{C}$, which is better at a tolerance of more $10^{\circ} \mathrm{C}$. The study showed that a diode can enhance the mechanical and thermal property of the compound.
\end{abstract}

Keywords: mechanical properties, thermal properties, dental resin, nano composite, diode Laser.

\section{Introduction}

Properties of resin-based materials are extremely different because they affected by many operators, such as Hardness, compressive, tensile strength and raise temperature matter depend on composite material, exposure time, lightcuring unit, radiance, emitted light spectrum and increase thickness [1, 2] . Hardness indicates for matter durability to the indentation and is one for most significant properties, been associated with compressive strength and resistance [3] . Hardness of composite materials affected by water with hydrolysis. Lower hardness of resin composite indicates poor physical connecting between the matrix and filler interface [4]. 
First of all, most visual adhesives with visible from the visible spectrum of light it is sensitive to the blue part of the light and its highest absorption is $470 \mathrm{~mm}$. The wavelength outside blue band is no effect to activate the polymerization response [5-7].

Light output properties were found from visible light processing units commonly applied not consistent.4,6 The devices produce the light which has a wide bandwidth $(120 \mathrm{~nm})$ typically fall between $(400-520 \mathrm{~nm})$ [8].The result energy density is around $400 \mathrm{~mW} / \mathrm{cm} 2$, with the light intensity disintegrate at a geometric progression to distance and laser radiation own single narrow strap for wavelength which traveling in waves that is equal in phase spatially and temporally. Diode laser works during a bandwidth which include $42 \mathrm{~nm}$ between (454 - 496) $\mathrm{nm}$ for the visible spectrum of intensity that equal $800 \mathrm{~mW} / \mathrm{cm} 2$ [9-13].

The radical polymerization given at, Propagation and Termination that have individual average for a polymerization; a monomers grow for polymers under a reaction of a radical series for polymerization. Photo chemistries explain the interaction light with the material to it induce a chemical reaction. The chemical reaction of light-treated teeth occurs at the ultraviolet and visible wavelengths for electromagnetic spectrum. A two molecules in a special arranging choose tupe of starting polymerization, and the imposed electromagnetic energy equation is[14, 15].

$$
h v=h c / \lambda
$$

Directness:

$$
\mathbf{I}=\mathbf{h c} / \lambda
$$

$\lambda=$ Incident Light Wavelength .

$\mathrm{h}=$ Planck's const.

$\mathrm{c}=$ Light Velocity .

Induction to polymerization induces light on free radicals or ion and is commensurately to the monomer concentration. No light effect on the chain of diffusion. An important advantage in dentistry is the beginning of a large range of temperatures [16].

The goal of the present work is to estimate the impact of direct and a reflect light off continues wave laser diode to cure a resin-based material for hardness, compression strength and high temperature.

\section{Materials and method}

Light healing dental composite tested in the work is Ivoclar Vivadent Tetric Nano Ceram composite material Figure $(1$, a). The specimens are cured stratifing diode laser beam in a wavelength for $(405 \mathrm{~mm})$ Figure $(1, \mathrm{~b})$.
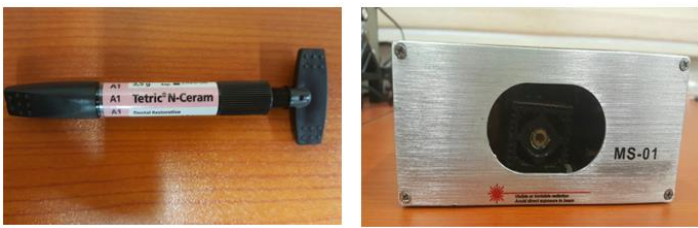

Fig. 1. a) Nano-hybrid co mposite b) diode laser. 
Using the light detector before polymerization, the laser diode beam was measured. The BNC (Bayonet Neill-Councilman) connector output is a direct photo current out of a photodiode and the function of an incident light power (p) and wavelength $(\lambda)$ can be got from a spectral responsively curve contened in data sheets for DET 10 A detectors, we transformed a photo current to the voltage (Vout) for viewing a digital voltmeter. This completed by add the external load resistance $\mathrm{R}_{\text {load }}$ output power divided :

$$
P_{\text {out }}=\frac{V_{\text {out }}}{R(A)} \times R_{\text {load }}
$$

All other specifications find by data sheet of the DET 10 A detectors, Then the laser beam diode power was checked and recorded and it appeared that the direct laser diode was $(86.30 \mathrm{~mW})$, while the laser diode reflection capacity was $(\mathrm{W} 3.68 \mathrm{~mW})$.

The samples were prepared using a $12 \mathrm{~mm}$ diameter conical stainless steel mold. The thickness of $1.5 \mathrm{~mm}$ of hardness and strength was blocked mold and then solved on the maps of the Islamic world and the bottom was installed a glass slide in the top three samples used for each group were polymerized for one minute Figure (2).

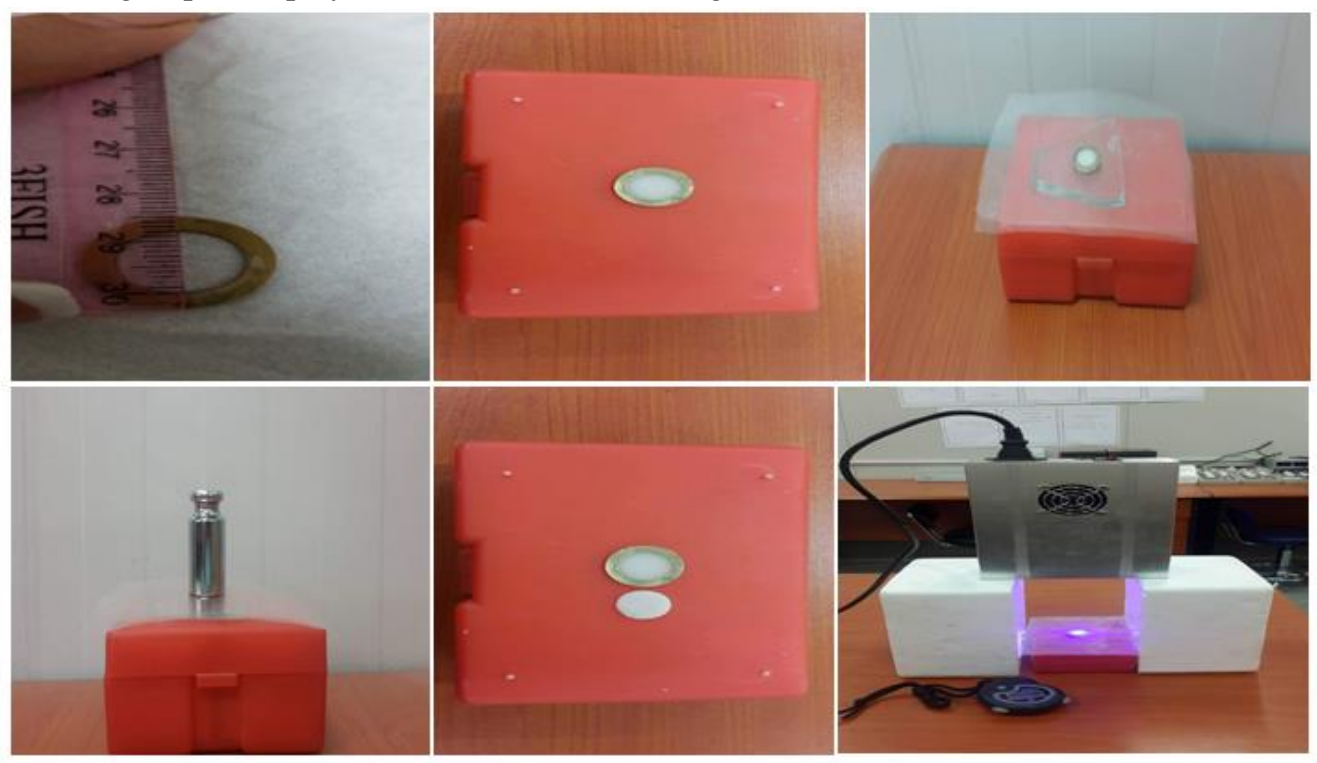

Fig.2. Method of preparing models and irradiation by diode laser diode.

\subsection{Thermal properties}

The $\mathrm{L}$ digital thermocouple use of measuring temperature from Nano Ceram and a time of laser radiation was recorded. The high temperature was evaluated every 10 seconds during laser (reflect and direct) radiation for 60 seconds. Temperature measurement repeat three times after a one hour standby period Figure $(3, a)$. 


\subsection{Mechanical properties}

a) Hardness: (Amsler, KARL-KOLB / Germany) The test used to measure the hardness in Figure $3 \mathrm{~b}$. The test load is set at $(1 \mathrm{~kg})$, the period of contact between difficulty and a solid 30 seconds. Measurements were taken directly from the scale, allowing five readings.

b)

c) Compression strength: The samples were cylindrical in size (12 x 1.5) Before the sample, all the samples were immersed in distilled water. Each sample was placed between two surfaces requiring high care axial loading, and eventually applied evenly. Intensity of pressure calculated on $(10,20,30,40,50,60)$, such as voltage in $\left(\mathrm{N} / \mathrm{mm}^{2}\right.$.

Compressive Strength $=$ Force at failure $(\mathrm{F})$ by newton over Minimum cross sectional area (A) by squar melemeter.

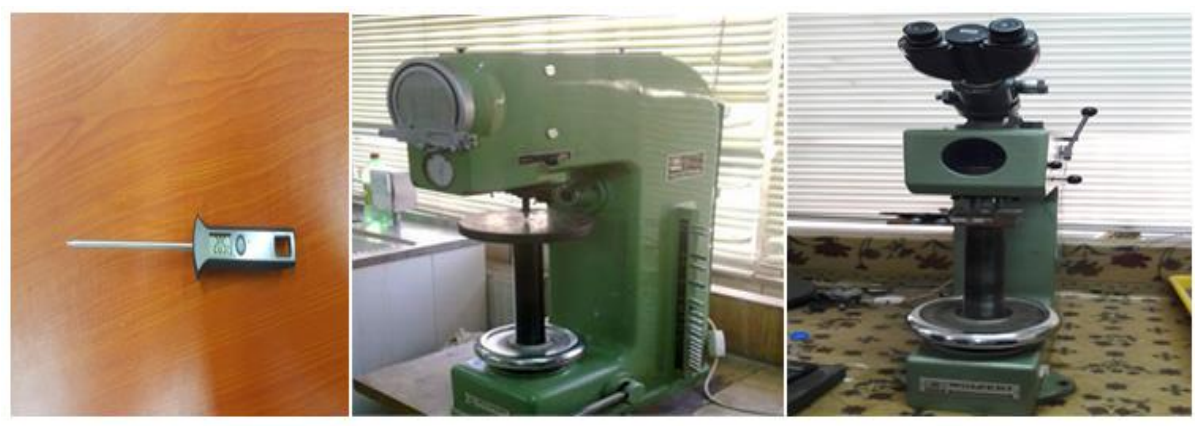

Fig.3. a.The L digital thermocouple; b.Amsler, KARL-KOLB machine; c. A universal testing machines

\section{Results and discussion}

Table (1,2,3 and 4) and figs. (4,5.6 and 7) the results were experimented with the average (hardness, pressure strength and temperature) of the active disk polymerized by a diode laser as a function of the time that was compared with statistics (logarithmic linear, quadratic, linear and energy) . 
Table 1. Mean hardness equally a function of exposure time with different thickness.

\begin{tabular}{|c|c|}
\hline Exposure Time (Sec) & Hardness Mean (VHN) \\
\hline 10 & 1003 \\
\hline 20 & 1027 \\
\hline 30 & 1041 \\
\hline 40 & 1077 \\
\hline 50 & 1103 \\
\hline 60 & 1219 \\
\hline
\end{tabular}

Table2. Compressive strength equally a function of exposure time.

\begin{tabular}{|c|c|}
\hline Exposure time (sec) & $\begin{array}{c}\text { Mean of Compressive strength } \\
\left(\mathrm{N} / \mathrm{mm}^{2}\right)\end{array}$ \\
\hline 10 & 163.742 \\
\hline 20 & 195.873 \\
\hline 30 & 226.345 \\
\hline 40 & 258.632 \\
\hline 50 & 218.981 \\
\hline 60 & 296.432 \\
\hline
\end{tabular}


Table3. Mean Temperature increase with exposure time of N-Ceram Light Cured for direct diode laser.

\begin{tabular}{|c|c|}
\hline Exposure Time $(\mathrm{Sec})$ & Mean Temperature rise $\left({ }^{\circ} \mathrm{c}\right)$ \\
\hline 10 & 1.6 \\
\hline 20 & 2.7 \\
\hline 30 & 3.3 \\
\hline 40 & 4.1 \\
\hline 50 & 4.9 \\
\hline 60 & 5.4 \\
\hline
\end{tabular}

Table4. Mean Temperature increase with exposure time of N-Ceram Light Cured for reflecting diode laser.

\begin{tabular}{|c|c|}
\hline Exposure Time (Sec) & Mean Temperature rise $\left({ }^{\circ} \mathrm{c}\right)$ \\
\hline 10 & 1 \\
\hline 20 & 1.3 \\
\hline 30 & 1.5 \\
\hline 40 & 1.7 \\
\hline 50 & 1.9 \\
\hline 60 & 2 \\
\hline
\end{tabular}




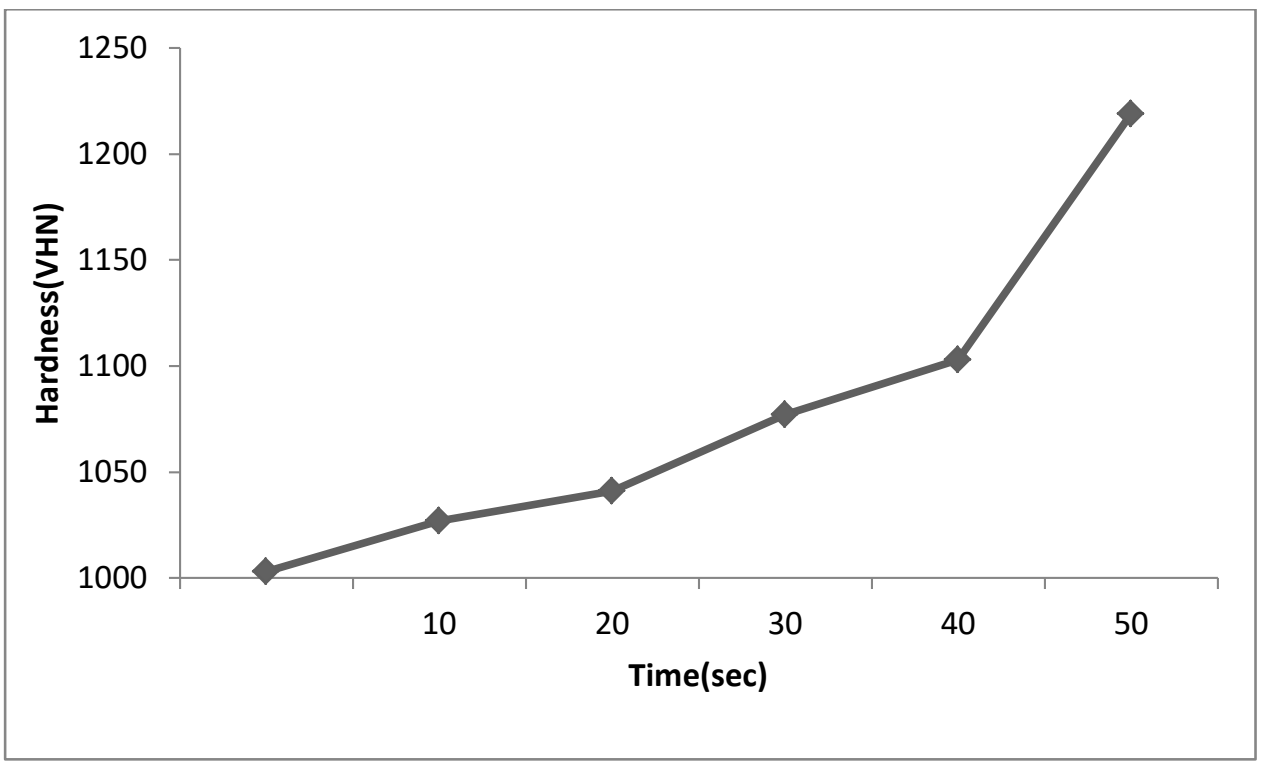

Fig. 4. The hardness (VHN) equally a function of exposure time.

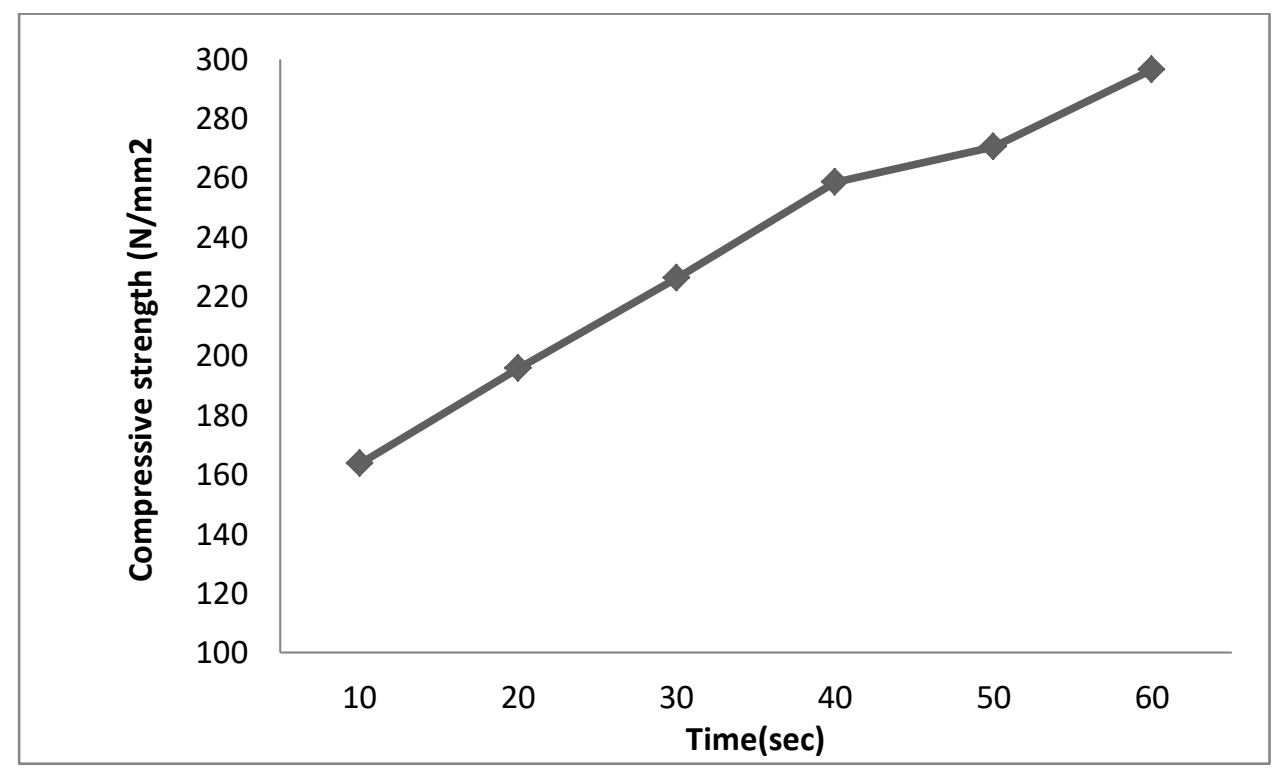

Fig. 5. The value of compressive strength as a function of time of experience. 


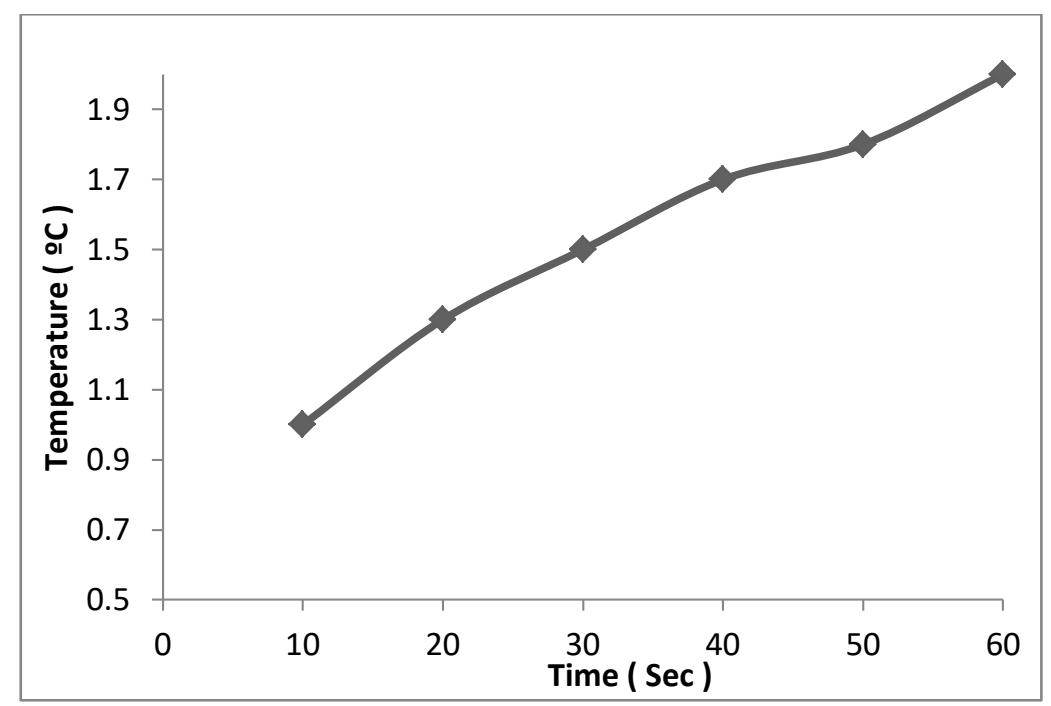

Fig.6. The relationship between temperature increases with time exposure to reflect diode laser radiation.

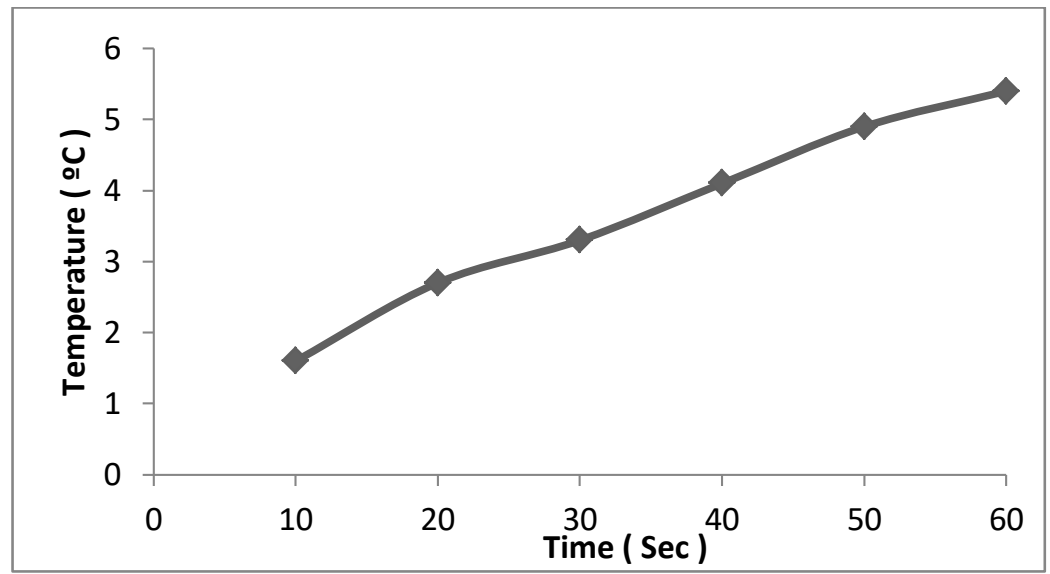

Fig.7. The relation between temperature increase with exposure time for direct diode laser radiation.

\section{Discussion}

Results showed longer irradiation time to be more effective in polymerization than the small irradiation time due to the spread of the lengthy irradiation time in deep parts of the model where it converts all the monomers to the polymer and this provides moral polymerization leading to moral mechanical properties [17]. The hardness experiment proved to more effective in the treatment of resin.The compressive strength showed the samples treated with laser diodes were high due to good polymerization enhanced by the laser diode. 
Increasing the temperature of the compound resin during polymerization reduces the processing time. Concerns may arise regarding the effect of use high temperature compound on tooth paste that causes damage to the tooth structure. However, the minimum temperature recorded in the reflective laser diode method was $2^{\circ} \mathrm{c}$ and the maximum temperature during irradiation with direct radiation to the diode laser was $5.4^{\circ} \mathrm{C}$, which are better at a tolerance of more than $10^{\circ} \mathrm{C}[18,19]$.

This study is a research, evaluate and compare the hardness, compressive strength and laser temperature. Different times of nano ceramic material. The study showed diode can enhance the mechanical and thermal properties of the compound.

\section{Conclusion}

The diode laser beam was applied to initiate photo polymerization of experimental dental Nano composites. Laser radiation has been promoted to treat resin, but its high cost and technical sensitivity have limited its use. Results obtained using eflect light and have a direct effect ongoing wave laser diode at low-density and wavelength of $405 \mathrm{NM}$ were promising, especially with regard to low temperature rise in composite material samples. We got the fact that the laser's ability to polymerize the sample is efficient for photo therapy. Diode laser described as a promising light source for treatment whose wavelength is significantly absorbed by the initiator in composite resin and provides compressive strength for those in the traditional light treatment system To ensure light intensity efficiency and to improve processing values it is necessary to use more blue diodes and focus their light.

\section{Acknowledgments.}

This research was supported by the Science and Engineering Research Program through the University of Hamdaniya and Northern Technical University, funded by the Ministry of Higher Education and Research / Republic of Iraq. (No. 00117 - 2020).

\section{References}

[1] Santini A. Current status of visible light activation units and the curing of light-activated resinbased composite materials. Dental update. 2010 May 2;37 (4): 214-27.

[2] Ruyter IE. Composites-characterization of composite filling materials: react or respond. Advances in dental research. 1988 Aug; 2 (1): 122-33.

[3] Li Y, Swartz ML, Phillips RW, Moore BK, Roberts TA. Materials science effect of filler content and size on properties of composites. Journal of Dental Research. 1985 Dec; 64 (12): 1396-403.

[4] Cramer NB, Stansbury JW, Bowman CN. Recent advances and developments in composite dental restorative materials. Journal of dental research. 2011 Apr; 90 (4): 402-16.

[5] Yildirim A, Bayindir M. Turn-on fluorescent dopamine sensing based on in situ formation of visible light emitting polydopamine nanoparticles. Analytical chemistry. 2014 May 14;86 (11): 5508-12.

[6] Burgess JO, Walker R, Davidson JM. Posterior resin-based composite: review of the literature. Pediatric dentistry. 2002;24(5):465-79. 
[7] Argun AA, Aubert PH, Thompson BC, Schwendeman I, Gaupp CL, Hwang J, Pinto NJ, Tanner DB, MacDiarmid AG, Reynolds JR. Multicolored electrochromism in polymers: structures and devices. Chemistry of materials. 2004 Nov 16;16(23):4401-12.

[8] Lalani N, Foley TF, Voth R, Banting D, Mamandras A. Polymerization with the argon laser: curing time and shear bond strength. The Angle Orthodontist. 2000 Feb;70(1):28-33.

[9] Tuchin VV. Light-tissue interactions. Biomedical Photonics Handbook. 2003:3-1.

[10] Kliger DS, Lewis JW. Polarized light in optics and spectroscopy. Elsevier; 2012 Dec 2.

[11] Vershchaka S.M. and Karash E. T.. ( Experimental model of the semicircular laminated composite curved bars). International Journal of Structronics \& Mechatronics. 2012, 1 (1),pp 67-73.

[12] Vershchaka S.M. and Karash E. T. (Experimental study of thin-walled structural fiberglass elements). Компрессорное и энергетическое машиностроение,2012, pp 28.

[13] McManamon PF, Dorschner TA, Corkum DL, Friedman LJ, Hobbs DS, Holz M, Liberman S, Nguyen HQ, Resler DP, Sharp RC, Watson EA. Optical phased array technology. Proceedings of the IEEE. $1996 \mathrm{Feb} ; 84(2): 268-98$

[14] Van Noort R. (Introduction to dental materials) Edinburgh, 2009

[15] Uhl A, Mills RW, Jandt KD. (Polymerization and light-induced heat of dental composites cured with LED and halogen technology) Biomater. 2003; 24:1809-1820.

[16] Uhl A, Völpel A, Sigusch BW.(Influence of heat from light curing units and dental composite polymerization on cells in vitro) J Dent. 2006 Apr;34(4):298-306.

[17] Charlesby A. Atomic radiation and polymers: international series of monographs on radiation effects in materials. Elsevier;2016Jun6.

[18] Bahrololoomi Z, Birang R, Chiniforush N, Yousefshahi H, Foroughi E. Thermal Changes of Root Surface of Anterior Primary Teeth in Pulpectomy with Er: YAG Laser. Journal of dentistry (Tehran, Iran). 2018 May;15(3):178.

[19] Shin DH, Yun DI, Park MG, Ko CC, Garcia-Godoy F, Kim HI, Kwon YH. Influence of DPSS laser on polymerization shrinkage and mass change of resin composites. Photomedicine and laser surgery. 2011 Aug 1;29(8):545-50. 